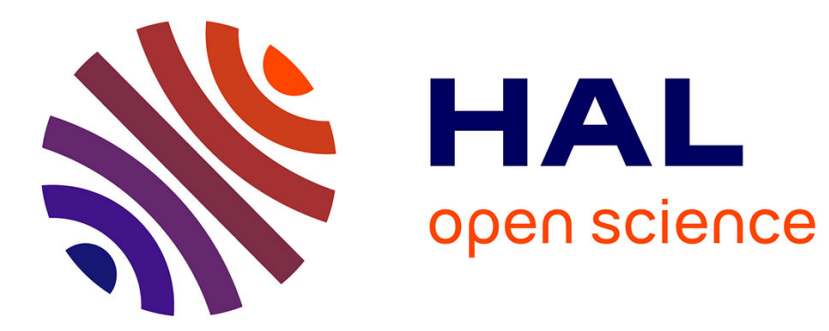

\title{
Resistance switching in HfO2 metal-insulator-metal devices
}

Patrice Gonon, Mathieu Mougenot, Christophe Vallée, Corentin Jorel, Vincent Jousseaume, Hélène Grampeix, Fadhel El Kamel

\section{To cite this version:}

Patrice Gonon, Mathieu Mougenot, Christophe Vallée, Corentin Jorel, Vincent Jousseaume, et al.. Resistance switching in HfO2 metal-insulator-metal devices. Journal of Applied Physics, 2010, 107 (7), pp.074507. 10.1063/1.3357283 . hal-00635956

\section{HAL Id: hal-00635956 https://hal.science/hal-00635956}

Submitted on 27 Oct 2011

HAL is a multi-disciplinary open access archive for the deposit and dissemination of scientific research documents, whether they are published or not. The documents may come from teaching and research institutions in France or abroad, or from public or private research centers.
L'archive ouverte pluridisciplinaire HAL, est destinée au dépôt et à la diffusion de documents scientifiques de niveau recherche, publiés ou non, émanant des établissements d'enseignement et de recherche français ou étrangers, des laboratoires publics ou privés. 


\section{AIP Applied Physics}

\section{Resistance switching in $\mathrm{HfO} 2$ metal-insulator-metal devices}

P. Gonon, M. Mougenot, C. Vallée, C. Jorel, V. Jousseaume et al.

Citation: J. Appl. Phys. 107, 074507 (2010); doi: 10.1063/1.3357283

View online: http://dx.doi.org/10.1063/1.3357283

View Table of Contents: http://jap.aip.org/resource/1/JAPIAU/v107/i7

Published by the American Institute of Physics.

\section{Additional information on J. Appl. Phys.}

Journal Homepage: http://jap.aip.org/

Journal Information: http://jap.aip.org/about/about_the_journal

Top downloads: http://jap.aip.org/features/most_downloaded

Information for Authors: http://jap.aip.org/authors

\section{ADVERTISEMENT}

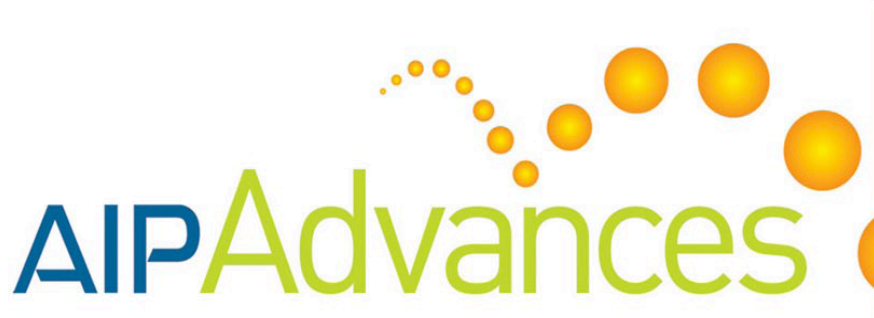

Submit Now

Explore AIP's new

open-access journal

- Article-level metrics now available

Join the conversation! Rate \& comment on articles 


\title{
Resistance switching in $\mathrm{HfO}_{2}$ metal-insulator-metal devices
}

\author{
P. Gonon, ${ }^{1, a)}$ M. Mougenot, ${ }^{1}$ C. Vallée, ${ }^{1}$ C. Jorel, ${ }^{1}$ V. Jousseaume,${ }^{2}$ H. Grampeix ${ }^{2}$ \\ and F. El Kamel ${ }^{3}$ \\ ${ }^{1}$ Microelectronics Technology Laboratory (LTM), Joseph Fourier University, French National Research \\ Center (CNRS), 17 Avenue des Martyrs, 38054 Grenoble Cedex 9, France \\ ${ }^{2}$ MINATEC, CEA-LETI, 17 Avenue des Martyrs, 38054 Grenoble Cedex 9, France \\ ${ }^{3}$ Laboratory for the Organization and Properties of Materials (LMOP), El Manar University, Tunis 1060, \\ Tunisia
}

(Received 14 December 2009; accepted 3 February 2010; published online 9 April 2010)

\begin{abstract}
Resistance switching is studied in $\mathrm{Au} / \mathrm{HfO}_{2}(10 \mathrm{~nm}) /\left(\mathrm{Pt}\right.$, TiN) devices, where $\mathrm{HfO}_{2}$ is deposited by atomic layer deposition. The study is performed using different bias modes, i.e., a sweeping, a quasistatic and a static (constant voltage stress) mode. Instabilities are reported in several circumstances (change in bias polarity, modification of the bottom electrode, and increase in temperature). The constant voltage stress mode allows extracting parameters related to the switching kinetics. This mode also reveals random fluctuations between the ON and OFF states. The dynamics of resistance switching is discussed along a filamentary model which implies oxygen vacancies diffusion. The rf properties of the ON and OFF states are also presented (impedance spectroscopy). (C) 2010 American Institute of Physics. [doi:10.1063/1.3357283]
\end{abstract}

\section{INTRODUCTION}

Resistance switching is a phenomenon by which some electrical insulators display a change in resistance upon application of a bias voltage. Such a phenomenon was observed several decades ago ${ }^{1}$ and has been widely studied in 1970s. ${ }^{2}$ More recently, the subject gained a new interest for the fabrication of nonvolatile memories, named resistive random access memories (RRAMs). Last progresses in the field have been reviewed by Waser et al. ${ }^{3}$ Resistance switching has been observed in several classes of oxides, including binary metal oxides $\left(\mathrm{NiO}, \mathrm{TiO}_{2}, \mathrm{ZrO}_{2}, \mathrm{Cu}_{\mathrm{x}} \mathrm{O}\right.$, etc.), perovskites $\left(\mathrm{BaTiO}_{3}, \quad \mathrm{SrTiO}_{3}, \quad\right.$ etc.), and manganites $\left(\mathrm{Pr}_{1-\mathrm{x}} \mathrm{Ca}_{\mathrm{x}} \mathrm{MnO}_{3}, \mathrm{La}_{1-\mathrm{x}} \mathrm{Sr}_{\mathrm{x}} \mathrm{MnO}_{3}\right.$, etc.). Despite several years of research efforts, the origin of resistance switching is still uncertain. Several models were proposed to explain the effect, such as space charge limited currents, field-driven Mott insulator-metal transition, Schottky barrier modification at electrodes, or formation of conducting filaments upon fieldenhanced migration of cations or anions across the film's thickness (filamentary model).

In the filamentary model, oxygen vacancies seem to play an important role. A widely accepted mechanism is the following. ${ }^{3}$ Oxygen is extracted from the oxide at the anode, leaving oxygen vacancies $\left(\mathrm{V}_{\mathrm{O}}^{2+}\right)$ under the anode and oxygen ions $\left(\mathrm{O}^{2-}\right)$ within the anode (oxide reduction, $\mathrm{HfO}_{2}$ $\rightarrow \mathrm{HfO}_{2-\mathrm{x}}+\mathrm{xV}_{\mathrm{O}}^{2+}+\mathrm{xO}^{2-}$ ). Oxygen vacancies are drifted by the electric field to the cathode and filaments containing $\mathrm{V}_{\mathrm{O}}^{2+}$ defects grow from the cathode to the anode. These filaments are conducting, possibly through carrier hopping between $\mathrm{V}_{\mathrm{O}}^{2+}$ related defects. ${ }^{4}$ When a filament comes into contact with the anode the electrodes are short-circuited and the device switches in a conducting state (ON state). When the voltage polarity is reversed, $\mathrm{V}_{\mathrm{O}}^{2+}$ are repelled from the anode

\footnotetext{
${ }^{a)}$ Author to whom correspondence should be addressed. Electronic mail: patrice.gonon@cea.fr.
}

(former cathode), the filament in contact with the anode is broken, and the device switches back to an insulating state (OFF state). Slight variants were proposed. For instance, it was outlined that since oxygen vacancies are positively charged, they never come into contact with the anode. ${ }^{3}$ In that case switching is viewed as a modulation of the filament tip/anode distance. When the $\mathrm{V}_{\mathrm{O}}^{2+}$ filament is in close proximity of the anode $(<2 \mathrm{~nm})$ the $\mathrm{ON}$ state is established through a tunneling conduction between the filament tip and the anode. Conversely, when the filament tip/anode distance is large (bias polarity is reversed), the device is in the OFF state. $^{3}$ This idea was recently developed in details by Pickett et $a .^{5}$ In the filamentary model, the ON-to-OFF transition requires to reverse the bias polarity (bipolar device). However, in many devices it is also observed that the OFF state can be restored by applying a bias of the same polarity (unipolar device). In such devices the ON-to-OFF transition is ascribed to Joule heating which leads to the thermal dissolution of conducting filaments.

Compared to oxides so far studied for RRAMs, $\mathrm{HfO}_{2}$ has the advantage of being more mature from a technological point of view. This dielectric has been widely studied as a high-k gate oxide, and hafnium-based dielectrics are now being introduced for advanced Complementary Metal Oxide Semiconductor (CMOS) gates. ${ }^{6}$ Therefore, as far as ease of integration is concerned, $\mathrm{HfO}_{2}$ would be an interesting candidate for the RRAM technology. Some works on the resistance switching properties of $\mathrm{HfO}_{2}$ were recently published. ${ }^{7-12}$ Lee et al. ${ }^{10}$ studied $\mathrm{Ru} / \mathrm{HfO}_{2} /$ TiN stacks and postulated that switching occurs at the $\mathrm{Ru} / \mathrm{HfO}_{2}$ interface whose properties are controlled by the amount of oxygen at this interface. The same authors recently introduced an $\mathrm{AlCu}$ buffer layer to improve memory performances. ${ }^{8}$ In $\mathrm{Au} / \mathrm{HfO}_{2} / \mathrm{Pt}$ structures oxygen deficiency was observed at the $\mathrm{HfO}_{2} / \mathrm{Pt}$ interface. ${ }^{9}$ The above results show that the metal/ $/ \mathrm{HfO}_{2}$ interface plays an important role. Bulk crystal- 
linity appears as a significant parameter as well. In $\mathrm{Pt} / \mathrm{HfO}_{2} / \mathrm{Pt}$ memory performances are enhanced upon postannealing. ${ }^{11}$ It was concluded that, in the ON state, conducting filaments are formed at grain boundaries. ${ }^{11}$ Chan et al., ${ }^{12}$ who studied $\mathrm{Au} / \mathrm{HfO}_{2} / \mathrm{Pt}$ devices, reported that switching proceeds in crystalline films, but not in amorphous ones. These authors attributed the switching to the migration of oxygen vacancies along grain boundaries. Walczyk et $a l^{7}$ reported that reliable switching in $\mathrm{Au} / \mathrm{HfO}_{2} / \mathrm{TiN}$ devices was only observed in $\mathrm{HfO}_{2}$ films whose thickness is above $20 \mathrm{~nm}$. Regarding switching polarity (unipolar or bipolar), different results were published. $\mathrm{HfO}_{2}$ films were reported to be unipolar, ${ }^{7,10,11}$ bipolar, ${ }^{8}$ both unipolar and bipolar, ${ }^{9}$ or changing from unipolar to bipolar after oxygen annealing. ${ }^{12}$ This brief survey shows that more studies are needed to understand resistance switching in $\mathrm{HfO}_{2}$.

In this work we study $\mathrm{Au} / \mathrm{HfO}_{2} /(\mathrm{Pt}$ or $\mathrm{TiN})$ structures. Resistance switching is studied using different dc bias modes, i.e., a sweeping mode, a quasistatic mode, and a static (constant voltage stress) mode. The ac electrical characteristics of the ON and OFF states are also reported. The roles of the bias polarity, of the electrodes, and of the temperature in the stability of the ON state are underlined. In a constant voltage stress mode, an interesting behavior is observed. In this mode, the sample's resistance is unstable, switching between the OFF and ON states as time elapses. Results are discussed along the oxygen vacancy-based filamentary model.

\section{EXPERIMENT}

$\mathrm{HfO}_{2}$ films $(10 \mathrm{~nm})$ were grown at $350{ }^{\circ} \mathrm{C}$ by atomic layer deposition (ALD) using alternate cycles of $\mathrm{H}_{2} \mathrm{O}$ and $\mathrm{HfCl}_{4}$ precursors (1 Torr) on Pt $(100 \mathrm{~nm}) / \mathrm{Ti}(10 \mathrm{~nm}) / \mathrm{Si}$ wafers. For the purpose of comparison, some films were also deposited on TiN $(60 \mathrm{~nm}) / \mathrm{Ti}(40 \mathrm{~nm}) / \mathrm{Si}$ wafers. Top gold electrodes (100 nm thick, $2 \mathrm{~mm}$ in diameter) were deposited on the $\mathrm{HfO}_{2}$ films by dc-sputtering. Electrical measurements (dc modes) were performed in air using a Keithley 2635 Source Meter unit, with the bottom electrode grounded. During switching from the OFF to the ON state the current is limited to $0.1 \mathrm{~mA}$ (current compliance) to avoid samples breakdown. Impedance spectroscopy (ac characteristics) were carried out using a Novocontrol analyzer working in the $1 \mathrm{~Hz}-100 \mathrm{kHz}$ frequency range.

Structural properties of $\mathrm{HfO}_{2}$ films were studied using angle-resolved x-ray photoelectron spectroscopy (ARXPS), IR spectroscopy and ellipsometry. Results of these characterizations can be found elsewhere. ${ }^{13}$ Briefly, it was found that the films are crystallized in the monoclinic phase. Their gap is around $5.5 \mathrm{eV}$. ARXPS performed on thinner films $(2 \mathrm{~nm})$ deposited on Pt reveals a homogeneous composition across the thickness with a sharp $\mathrm{HfO}_{2} / \mathrm{Pt}$ interface (absence of $\mathrm{PtO}$ oxides). On the contrary, films deposited on TiN show the presence of $\mathrm{TiO}_{\mathrm{x}} \mathrm{N}_{\mathrm{y}}$ and $\mathrm{TiO}_{2}$ at the $\mathrm{HfO}_{2} / \mathrm{TiN}$ interface. ${ }^{13}$
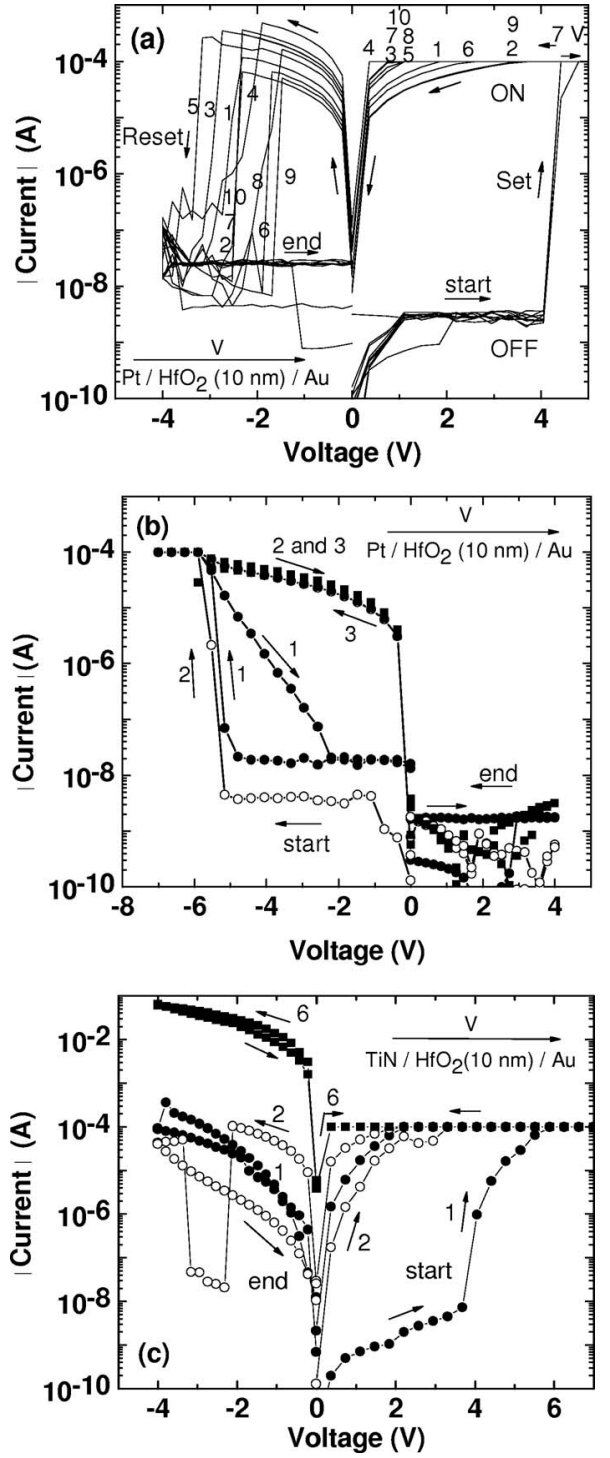

FIG. 1. I-V characteristics in a sweeping mode $(0.35 \mathrm{~V} / \mathrm{s})$ for (a) $\mathrm{Au} / \mathrm{HfO}_{2} / \mathrm{Pt}$ stacks when submitted to positive cycles $(0 \mathrm{~V} \rightarrow+7 \mathrm{~V}$ $\rightarrow 0 \mathrm{~V} \rightarrow-4 \mathrm{~V} \rightarrow 0 \mathrm{~V}$ ), (b) $\mathrm{Au} / \mathrm{HfO}_{2} / \mathrm{Pt}$ stacks when submitted to negative cycles $(0 \mathrm{~V} \rightarrow-7 \mathrm{~V} \rightarrow 0 \mathrm{~V} \rightarrow+4 \mathrm{~V} \rightarrow 0 \mathrm{~V})$, and (c) $\mathrm{Au} / \mathrm{HfO}_{2} / \mathrm{TiN}$ stacks when submitted to positive cycles $(0 \mathrm{~V} \rightarrow+7 \mathrm{~V} \rightarrow 0 \mathrm{~V} \rightarrow-4 \mathrm{~V}$ $\rightarrow 0 \mathrm{~V})$. Cycles are numbered in sequence.

\section{RESULTS AND DISCUSSION}

\section{A. Sweeping mode}

Resistance switching was first tested in a sweeping mode $(0.35 \mathrm{~V} / \mathrm{s})$. Results are shown in Fig. 1. Figure 1(a) shows the characteristics of $\mathrm{Au} / \mathrm{HfO}_{2} / \mathrm{Pt}$ stacks when submitted to "positive" bipolar cycles $\left(\mathrm{V}_{\mathrm{Au} / \mathrm{Pt}}=0 \mathrm{~V} \rightarrow 7 \mathrm{~V} \rightarrow 0 \mathrm{~V} \rightarrow\right.$ $-4 \mathrm{~V} \rightarrow 0 \mathrm{~V})$. Ten successive cycles are shown in Fig. 1(a). Very good reproducibility is obtained for $\mathrm{V}_{\text {set }}(+4 \mathrm{~V})$, but large dispersion is observed for $\mathrm{V}_{\text {reset }}$ (between -1.5 and $-3.5 \mathrm{~V})$. Unipolar cycles were also tested. A first cycle $(0 \mathrm{~V} \rightarrow 7 \mathrm{~V} \rightarrow 0 \mathrm{~V}$, with current compliance) was applied to set the sample in the $\mathrm{ON}$ state. A second cycle $(0 \mathrm{~V}$ $\rightarrow 7 \mathrm{~V} \rightarrow 0 \mathrm{~V}$, no current compliance) was applied in order to reset the sample. However, such cycles systematically failed to restore the OFF state. In similar structures $\left(\mathrm{Au} / \mathrm{HfO}_{2} / \mathrm{Pt}\right.$ stacks $)$ both bipolar and unipolar behaviors 
were reported, ${ }^{9}$ which is not observed here. As opposed to previous works, ${ }^{7,9,10}$ it is also noticeable that the present films do not require a forming step. Indeed, the Set at $+4 \mathrm{~V}$ is recorded during the first voltage sweep.

In the OFF state it is observed that the current is constant as the voltage is varied [see Fig. 1(a), OFF state]. This is indicative of a capacitive current given by $\mathrm{I}=\mathrm{C}(\mathrm{dV} / \mathrm{dt})$. The capacitive current is related to the displacement current density $\mathrm{j}=\mathrm{dD} / \mathrm{dt}$, where $\mathrm{D}=\varepsilon_{0} \varepsilon_{\mathrm{r}} \mathrm{E}$ is the electric displacement field. Capacitance (C) _ of the devices is around $5 \times 10^{-8} \mathrm{~F}$ (see Sec. III F). Considering that $\mathrm{dV} / \mathrm{dt}=0.35 \mathrm{~V} / \mathrm{s}$, we obtain $\mathrm{I} \approx 10^{-8} \mathrm{~A}$, which is the order of magnitude observed for $\mathrm{I}$ in the OFF state [calculation is approximate because $\mathrm{V}(\mathrm{t})$ is not exactly a linear function, but a staircase one]. The capacitive current (OFF state) is observed until the voltage reaches $\mathrm{V}_{\text {set }}=+4 \mathrm{~V}$ exactly. At this point the device suddenly switches to the ON state. Since the delay time between two voltage increments is of $1 \mathrm{~s}$, the abrupt $\mathrm{OFF} \rightarrow \mathrm{ON}$ transition observed at $\mathrm{V}_{\text {set }}=+4 \mathrm{~V}$ suggests that near below $\mathrm{V}_{\text {set }}$, i.e at $\mathrm{V}=+3.7 \mathrm{~V}$ (the voltage that is applied before reaching $+4 \mathrm{~V}$ ), filament growth requires much more than $1 \mathrm{~s}$. If not, field-enhanced conduction should be observable between the filament tip and the anode (this will be observed later when studying the quasistatic mode, see Sec. III D). The corollary is that at $\mathrm{V}_{\text {set }}=+4 \mathrm{~V}$ (electric field of $4 \mathrm{MV} / \mathrm{cm}$ ) filaments growth occurs in a time scale shorter than $1 \mathrm{~s}$. This is consistent with Sec. III E, where it will be shown that filaments growth proceeds at a speed which varies exponentially with the electric field (diffusion of oxygen vacancies). Therefore, it can be concluded that filaments growth is almost null below $\mathrm{V}_{\text {set }}$, and occurs at fast speed at $\mathrm{V}_{\text {set }}$ (threshold voltage).

A highly reproducible $\mathrm{V}_{\text {set }}$ value from cycle to cycle, and the absence of forming, indicate that the filaments are completely "washed out" at each Reset. On the contrary case, i.e., if the Reset led to a partial rupture of filaments, we would expect to observe a varying $\mathrm{V}_{\text {set }}$ from cycle to cycle (we should at least observe a $V_{\text {set }}$ value which decreases from the first to the second cycle). At each Reset the filaments are fully destroyed, so at each Set the sample must be "formed" again. In a sense, each Set is a forming stage. It is believed that the small thickness of our samples $(10 \mathrm{~nm})$ allows a complete disappearance of filaments at Reset. In previous works ${ }^{7-12}$ the samples thickness is $20 \mathrm{~nm}$ or above, at Reset filaments are partially ruptured and $\mathrm{V}_{\text {set }}$ is lower than the forming voltage.

The fact that $\mathrm{V}_{\text {reset }}$ is fluctuating during successive cycles is more puzzling. Variation in $\mathrm{V}_{\text {reset }}$ appears to be random, without any correlation to the cycle number, nor any link to the current level in the ON state. An example is shown in Fig. 1. The ON current in both the third and the fourth cycle is higher than in the first cycle but $V_{\text {reset }}$ (fourth cycle) $<\mathrm{V}_{\text {reset }}$ (first) $<\mathrm{V}_{\text {reset }}$ (third). This shows that $\mathrm{V}_{\text {reset }}$ is not related to the resistance of the filament, or in another words to a Joule effect.

\section{B. Role of bias polarity}

Stability of the ON state depends on the bias polarity used to switch the device. A typical example is shown in Fig. 1(b). The device is the same as in Fig. 1(a) $\left(\mathrm{Au} / \mathrm{HfO}_{2} / \mathrm{Pt}\right)$, but a "negative" bipolar cycles is applied $\left(\mathrm{V}_{\mathrm{Au} / \mathrm{Pt}}=0 \mathrm{~V} \rightarrow\right.$ $-7 \mathrm{~V} \rightarrow 0 \mathrm{~V} \rightarrow+4 \mathrm{~V} \rightarrow 0 \mathrm{~V})$. An $\mathrm{OFF} \rightarrow \mathrm{ON}$ transition is observed at somewhat higher values $\left(\mathrm{V}_{\text {set }}=-5 \mathrm{~V}\right)$. More importantly, the ON state is not stable and it is lost when the voltage is swept back to $0 \mathrm{~V}$. During the first cycle the ON state is progressively lost, before the voltage comes back to 0 $\mathrm{V}$ [cycle 1 in Fig. 1(b)]. During the second cycle the ON state has a longer lifetime, and is lost only at short-circuit [cycle 2 in Fig. 1(b)]. In the third cycle, the ON state is recovered as soon as a negative voltage is applied, with no need to reach $\mathrm{V}_{\text {set }}=-5 \mathrm{~V}$. Again, the $\mathrm{ON}$ state is lost when coming back to $0 \mathrm{~V}$ [cycle 3 in Fig. 1(b)].

Why is the ON state not maintained for negative cycles? For negative cycles [Fig. 1(b)] oxygen vacancies are produced at the Pt electrode and $\mathrm{V}_{\mathrm{O}}^{2+}$ filaments grow from the $\mathrm{Au}$ electrode. The instability of the $\mathrm{ON}$ state indicates that $\mathrm{V}_{\mathrm{O}}^{2+}$ filaments grown on the Au top electrode are easily ruptured [Fig. 1(b)], while those grown on the Pt electrode are stable [Fig. 1(a)]. Several reasons can be imagined. The first one could be that the $\mathrm{V}_{\mathrm{O}}^{2+}$-metal binding energy is lower for $\mathrm{Au}$ than for Pt. This is confirmed by studies of metal adsorption energy on oxide surfaces which contain oxygen vacancies. For instance, in both $\mathrm{MgO}$ (Ref. 14) and $\mathrm{TiO}_{2}$ (Ref. 15), the $\mathrm{Pt}-\mathrm{V}_{\mathrm{O}}$ energy is higher than the $\mathrm{Au}-\mathrm{V}_{\mathrm{O}}$ binding energy (difference can be as high as $50 \%$, e.g., in $\mathrm{MgO}$ the $\mathrm{Pt}-\mathrm{V}_{\mathrm{O}}$ bond energy is of $581 \mathrm{~kJ} / \mathrm{mol}$ and is only of $311 \mathrm{~kJ} / \mathrm{mol}$ for $\mathrm{Au}-\mathrm{V}_{\mathrm{O}}$ ). ${ }^{14}$ Therefore, when filaments are grown on Au (negative cycles) it could be that $\mathrm{V}_{\mathrm{O}}^{2+}$ easily "unstick" from $\mathrm{Au}$ as the voltage is decreased. A second reason could be related to $\mathrm{O}^{2-}$ diffusion. When positive bias is applied on the top $\mathrm{Au}$ electrode [positive cycles, Fig. 1(a)], $\mathrm{O}^{2-}$ are extracted from the device and outdiffuse to the atmosphere through the $\mathrm{Au}$ electrode or at its periphery $\left(\mathrm{O}^{2-} \rightarrow \frac{1}{2} \mathrm{O}_{2}+2 \mathrm{e}^{-}\right)$. On the contrary, when positive bias is applied on Pt [negative cycles, Fig. 1(b)], $\mathrm{O}^{2-}$ ions are buried in this electrode and they cannot escape from the sample because $\mathrm{Pt}$ is the bottom electrode. When the electric field is removed $(\mathrm{V}=0 \mathrm{~V}), \mathrm{O}^{2-}$ diffuses back from the $\mathrm{Pt}$ electrode and leads to the rupture of $\mathrm{V}_{\mathrm{O}}^{2+}$ filaments $\left(\mathrm{O}^{2-}+\mathrm{V}_{\mathrm{O}}^{2+} \rightarrow \mathrm{O}_{\mathrm{O}}\right)$. Finally, as suggested by Jeong et al., ${ }^{16}$ oxygen diffusion through the Au top electrode can also retard the accumulation of oxygen vacancies at this electrode $\left(1 / 2 \mathrm{O}_{2}+2 \mathrm{e}^{-}+\mathrm{V}_{\mathrm{O}}^{2+} \rightarrow \mathrm{O}_{\mathrm{O}}\right)$. For negative cycles, the above hypotheses suggest that the filaments are partially ruptured at their extremity (at the Au- $\mathrm{V}_{\mathrm{O}}$ interface because of weak $\mathrm{Au}-\mathrm{V}_{\mathrm{O}}$ interaction or $\mathrm{O}_{2}$ diffusion, or at the $\mathrm{Pt}-\mathrm{V}_{\mathrm{O}}$ interface because of $\mathrm{O}^{2-}$ back-diffusion from $\mathrm{Pt}$ ).

\section{Role of bottom electrode}

Figure 1(c) shows the current-voltage (I-V) characteristics recorded for a TiN bottom electrode [keeping the same bias polarity as in Fig. 1(a)]. In this case it is difficult to reset the device. Cycle 1 shows a Set at $+4 \mathrm{~V}$, but it is not possible to get a Reset at $\mathrm{V}<0$. Reset is obtained during the second cycle, but the OFF state is unstable, and the device comes back to the ON state while pursuing the sweep toward negative voltages. Finally, after a few cycles the device breakdowns [cycle 6 in Fig. 1(c)]. The affinity of the metal 
(TiN) to oxygen could play a role. Because TiN has a strong affinity for oxygen, it could lead to oxygen depletion in the oxide, thereby creating a large amount of oxygen vacancies close to the interface. This in turn could explain that stronger filaments are formed, which are more difficult to reset.

It is also noted that switching (first cycle) does not proceed as abruptly as for Pt bottom electrodes. Instead, the OFF-to-ON transition is progressively established between 4 and $6 \mathrm{~V}$ [Fig. 1(c)]. Finally, for $\mathrm{V}<4 \mathrm{~V}$, a capacitive current is no longer observed, suggesting that other conduction mechanism dominates (such as electron injection from the TiN electrode). This is consistent with the fact that the work function of TiN $(5.1 \mathrm{eV})$ is lower than the Pt work function $(5.65 \mathrm{eV})$.

In these samples it was shown by ARXPS that the $\mathrm{TiN} / \mathrm{HfO}_{2}$ interface contains a $2 \mathrm{~nm}$ interfacial layer composed of $\mathrm{TiO}_{\mathrm{x}} \mathrm{N}_{\mathrm{y}}$ and $\mathrm{TiO}_{2}$ phases. ${ }^{13}$ Before $\mathrm{HfO}_{2}$ deposition the TiN wafers were exposed to air and it is indeed known that upon exposure to air TiN oxidizes spontaneously to form $\mathrm{TiO}_{2}$ at its surface. ${ }^{17}$ Thus, the structure must be viewed as a $\mathrm{TiN} / \mathrm{TiO}_{\mathrm{x}} \mathrm{N}_{\mathrm{y}}(2 \mathrm{~nm}) / \mathrm{HfO} 2(10 \mathrm{~nm}) / \mathrm{Au}$ stack. At present the role played by the mixed $\mathrm{TiO}_{\mathrm{x}} \mathrm{N}_{\mathrm{y}}$ interfacial layer is unclear. Its adverse effect is to impede the Reset. It must be underlined that this behavior radically differs from the one observed in Ref. 7 where good and stable switching characteristics are recorded for $\mathrm{Au} / \mathrm{HfO}_{2} / \mathrm{TiN}$ stacks (which also contain a TiON interfacial layer at the bottom electrode). However, in Ref. 7 thicker films were used $(>20 \mathrm{~nm})$ and the authors pointed out that "unreliable" behavior was observed for thinner films (without any further details). Here 10 $\mathrm{nm}$ films are used, which may be considered as consistent with this observation.

Because we were unable to obtain reliable switching characteristics with $\mathrm{TiN}$, the rest of this paper will discuss only the data corresponding to the $\mathrm{Au} / \mathrm{HfO}_{2} / \mathrm{Pt}$ stacks.

\section{Quasistatic mode}

Resistance switching was further tested in a quasistatic mode [Fig. 2(a)]. In this mode the voltage is increased every $1 \mathrm{~min}$ and the current is read at the end of this time interval. In that case bulk polarization has time to establish, the displacement current vanishes $\left(\mathrm{D}=\varepsilon_{0} \mathrm{E}+\mathrm{P}=\right.$ const., $\left.\mathrm{dD} / \mathrm{dt}=0\right)$ and we observe the conduction current. The I-V characteristic is almost Ohmic up to $1 \mathrm{~V}$ and becomes supralinear above $1 \mathrm{~V}$. Again, the device switches at $\mathrm{V}_{\text {set }}=+4 \mathrm{~V}$ exactly. However, compared to the sweeping mode, the current steeply rises when reaching voltages close to $\mathrm{V}_{\text {set }}$. For instance, at $\mathrm{V}=+3.5 \mathrm{~V}$ the current in the quasistatic mode [Fig. 2(a)] is 100 times higher than in the sweeping mode [Fig. 1(a)]. Since $1 \mathrm{~min}$ is left after each voltage step (instead of $1 \mathrm{~s}$ in the sweeping mode), it is believed that above $1 \mathrm{~V}$ the filaments have time to partially grow. For such a situation the conduction is enhanced because it occurs between the anode and the filaments tips where the electric field is reinforced. Since at $\mathrm{V}=+3.5 \mathrm{~V}$ the device is still in the OFF state, it means that at $\mathrm{V}=+3.5 \mathrm{~V}$ the filaments need more than $1 \mathrm{~min}$ to grow from the cathode to the anode. This has to be com-
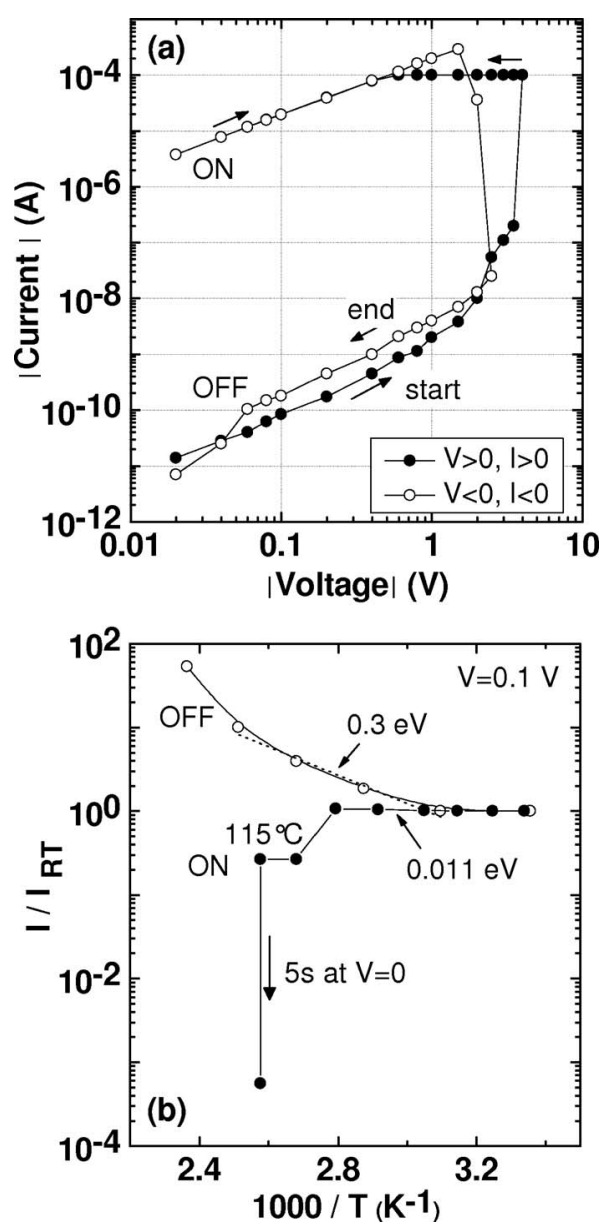

FIG. 2. (a) $\mathrm{I}-\mathrm{V}$ characteristic in a quasistatic mode (current is read $1 \mathrm{~min}$ after application of the bias voltage) and (b) temperature dependence of the $\mathrm{ON}$ and OFF states ( 3 min temperature steps). The current (I) is normalized to the room temperature current $\left(\mathrm{I}_{\mathrm{RT}}\right)$.

pared to less than $1 \mathrm{~s}$ at $\mathrm{V}=+4 \mathrm{~V}$ (see discussion in Sec. III A). These orders of magnitude will be confirmed later (Sec. III E).

In Fig. 2(a) the Reset part of the I-V curve $(\mathrm{V}<0)$ is superimposed on the Set part $(\mathrm{V}>0)$ to show that after the $\mathrm{ON} \rightarrow \mathrm{OFF}$ transition the OFF conduction level is the same as the one measured before the $\mathrm{OFF} \rightarrow \mathrm{ON}$ transition. This further supports the view that the filaments are totally destroyed at each Reset.

The temperature dependence of the $\mathrm{OFF}$ and $\mathrm{ON}$ states is depicted in Fig. 2(b) $\left(25{ }^{\circ} \mathrm{C}<\mathrm{T}<150{ }^{\circ} \mathrm{C}\right)$. During these measurements a constant bias of $0.1 \mathrm{~V}$ is maintained on the $\mathrm{Au}$ electrode (Ohmic part of the OFF and ON states). Once the desired temperature is reached the sample is left for three minute to stabilize, and the current is measured. In the OFF state the $\mathrm{I}(\mathrm{T})$ curve departs from an Arrhenius law and a single activation energy cannot be observed. At 1000/T $=2.8 \mathrm{~K}^{-1}\left(85^{\circ} \mathrm{C}\right)$ the slope of the $\mathrm{I}(1 / \mathrm{T})$ curve is around 0.3 $\mathrm{eV}$. Walczyk et al. ${ }^{7}$ observed the same activation energy and they ascribed it to an interstitial $\mathrm{H}$ related trap located at 0.3 $\mathrm{eV}$ below the conduction band. In Fig. 2(b) the absence of single activation energy indicates a distribution of states (band tail) around $0.3 \mathrm{eV}$.

In the ON state the activation energy is very low (11 $\mathrm{meV}$ ) and it is consistent with an tunnel hopping conduction 


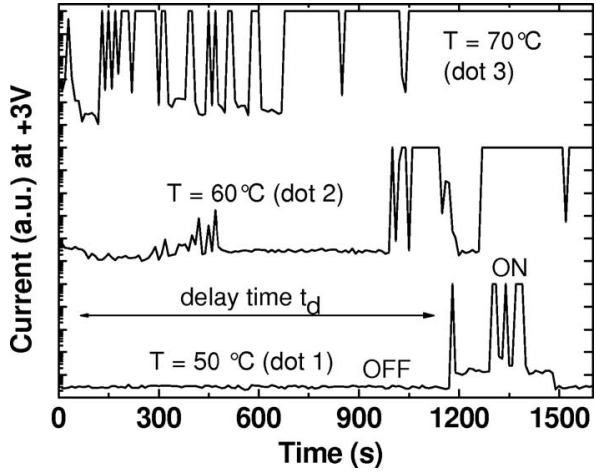

FIG. 3. I(t) recorded at a constant bias of $+3 \mathrm{~V}$, at different temperatures. A virgin dot is used at each temperature.

between localized states (vacancy related defects). ${ }^{4}$ When reaching temperatures around $100{ }^{\circ} \mathrm{C}$ the $\mathrm{ON}$ conductance (G) decreases. If the sample is short-circuited during a few seconds at $115^{\circ} \mathrm{C}$ the conductivity drops over three decades [Fig. 2(b)] to reach conductivity only one decade above the OFF state at the same temperature. This shows that the ON state is thermally unstable. Such instability can be understood by considering that thermal agitation acts again $\mathrm{V}_{\mathrm{O}}^{2+}$ alignment by the electric field. If the electric field is removed (sample is short-circuited), the field-induced filamentary structure can no longer be maintained and thermal agitation leads to a rapid dissolution of the filaments. Note that to observe such a rapid loss of the ON state (in a few seconds) it is necessary to go above $100{ }^{\circ} \mathrm{C}$. At room temperature the devices retain the $\mathrm{ON}$ state up to one day (the maximum retention period which was tested).

\section{E. Static [constant voltage stress (CVS)] mode}

In the preceding sections the filaments formation kinetics was evoked to explain the abrupt $\mathrm{OFF} \rightarrow \mathrm{ON}$ transition observed in the sweeping mode, as well as the high current levels observed near below $\mathrm{V}_{\text {set }}$ in a quasistatic mode. To gain more information on filaments formation kinetics the samples were studied under a CVS mode. A first series of experiments was conducted by applying a constant positive bias of $+3 \mathrm{~V}$ to the $\mathrm{Au} / \mathrm{HfO}_{2} / \mathrm{Pt}$ stack and the current was recorded as a function of time, at different temperatures (Fig. $3)$. Despite the fact that the bias $(+3 \mathrm{~V})$ is below $\mathrm{V}_{\text {set }}$ $(+4 \mathrm{~V})$, at a certain time the sample switches to the $\mathrm{ON}$ state. The first switch $(\mathrm{OFF} \rightarrow \mathrm{ON})$ is followed by successive switches between the OFF and the ON states, with random time intervals separating two switching events. In Fig. 3, it is apparent that the time to the first $\mathrm{OFF} \rightarrow \mathrm{ON}$ transition decreases as the temperature increases. In the following, this time (first $\mathrm{OFF} \rightarrow \mathrm{ON}$ transition) will be denoted the "delay time" $\left(\mathrm{t}_{\mathrm{d}}\right)$.

In Fig. 3, at each temperature a new (virgin) dot is used. We then performed successive CVS measurements on the same dot [Fig. 4(a)]. At each new temperature, before recording the $\mathrm{I}(\mathrm{t})$ the sample is reset by applying a positive bipolar cycle as the one used in Fig. 1(a) (Sec. III A). It is often argued that Reset occurs by a partial rupture of filaments. Thus, by using the same dot we expected to observe a de-
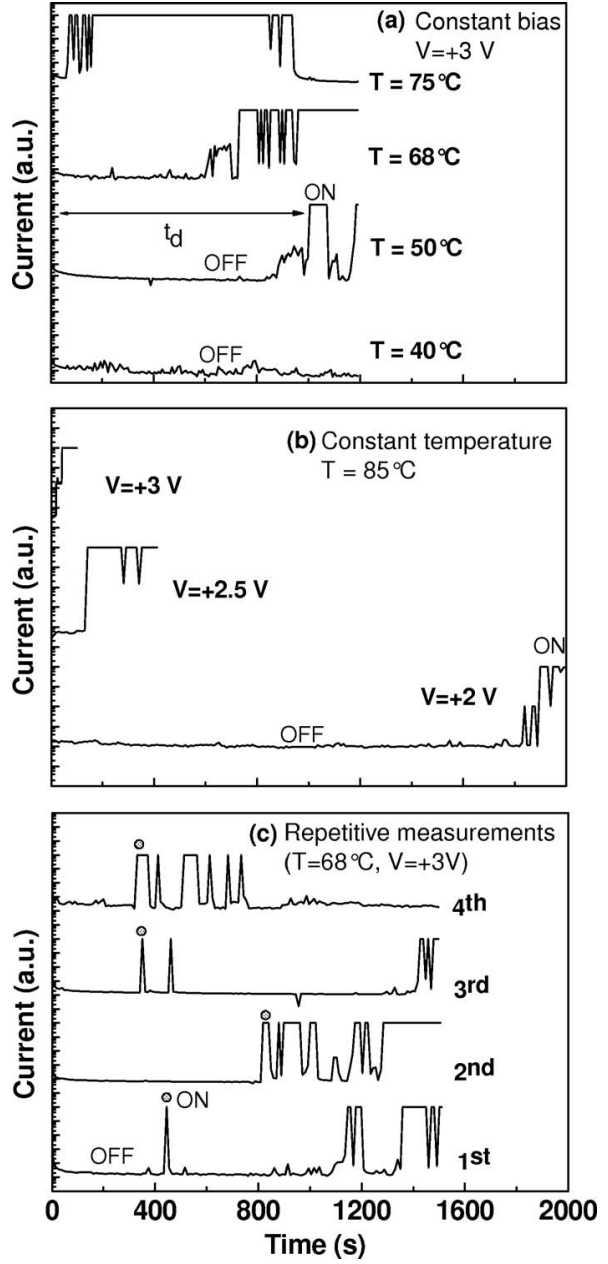

FIG. 4. I(t) characteristics recorded on the same dot, (a) at constant bias and different temperatures, (b) at constant temperature and different biases, and (c) at constant temperature and bias, at different times.

crease in the time to the first switching $\left(t_{d}\right)$, because only a part of the filament has to be reconstructed at each new experiment. This is not observed. When experiments are performed on the same dot the delay time $t_{d}$ is as long as the one measured for fresh dots [sometimes even larger, compare $\mathrm{T}$ $=70{ }^{\circ} \mathrm{C}$ in Fig. 3 and $\mathrm{T}=68{ }^{\circ} \mathrm{C}$ in Fig. 4(a)]. Again, this shows that a Reset restores the sample in a "fresh" state.

Figure 5(a) shows that $t_{d}$ is thermally activated with an activation energy around $1 \mathrm{eV}$. Within the hypothesis that the ON state corresponds to $\mathrm{V}_{\mathrm{O}}^{2+}$ path extending from the cathode to the anode, then $t_{d}$ is controlled by the slowest process

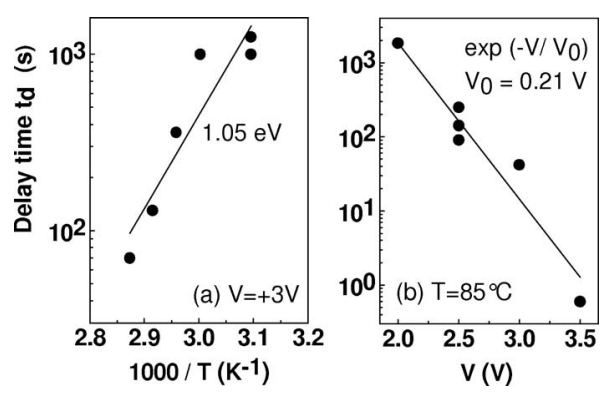

FIG. 5. Delay time $\left(t_{d}\right)$ plotted (a) as a function of temperature at constant bias and (b) as a function of bias at constant temperature. 
which takes part in the growth of the vacancy path. By referring to works on metallic dendrites growth in electrolytes $^{18}$ and to time-dependent switching in phase change memories (PCRAMs), ${ }^{19}$ the growth rate of vacancy filaments could be limited by the production of vacancies at the anode, to their nucleation at the cathode, ${ }^{19}$ or to their diffusion in the bulk. ${ }^{18}$ At present it is not possible to conclude on which of the above mechanisms controls $t_{d}$. Let us assume that $\mathrm{V}_{\mathrm{O}}^{2+}$ diffusion is the rate limiting step. Following Barton and Bockris, ${ }^{18}$ the dendrites growth rate $(\mathrm{v})$ in ionic solutions is proportional to the diffusion coefficient (D) of metal ions (Eq. 8 in Ref. 18). By analogy, we should have $t_{d} \sim 1 / v \sim D^{-1}$, where $D$ is the vacancy diffusion coefficient. It is expected that the diffusion barrier is lowered as the electric field is increased. This is observed in Fig. 4(b) where $t_{d}$ decreases as the bias is increased. Figure 5(b) shows that $t_{d}$ varies exponentially with $\mathrm{V}$ as $\mathrm{t}_{\mathrm{d}} \sim \exp \left(-\mathrm{V} / \mathrm{V}_{0}\right)$, where $\mathrm{V}_{0}$ $=0.21 \mathrm{~V}\left(\mathrm{~T}=85^{\circ} \mathrm{C}\right)$. These results are consistent with a field-enhanced diffusion for which $\mathrm{D}=\mathrm{D}_{0} \times \exp \left(-\mathrm{E}_{\mathrm{a}} / \mathrm{kT}\right)$ with $\mathrm{E}_{\mathrm{a}}=\mathrm{E}_{\mathrm{a} 0}-\mathrm{qFs}$, where $\mathrm{E}_{\mathrm{a} 0}$ is the activation energy at zero field, $\mathrm{F}$ is the electric field, and $\mathrm{s}$ is the hopping distance of $\mathrm{V}_{\mathrm{O}}^{2+}(\mathrm{q}=2 \mathrm{e})$. The term $(\mathrm{qFs})$ represents the barrier lowering due to the electric field. Since F=V/t, where $t$ is the film's thickness, we have $\mathrm{V}_{0}=\mathrm{tkT} / \mathrm{qs}$. At $\mathrm{T}=85^{\circ} \mathrm{C}, \mathrm{V}_{0}=0.21 \mathrm{~V}$ corresponds to $\mathrm{s}=7 \AA$. At $\mathrm{V}=+3 \mathrm{~V}$ we measured $\mathrm{E}_{\mathrm{a}}$ $=1.05 \mathrm{eV}$ [Fig. 5(a)]. Using $\mathrm{s}=0.7 \mathrm{~nm}$, the barrier lowering at $+3 \mathrm{~V}$ is $0.44 \mathrm{eV}$, thus $\mathrm{E}_{\mathrm{a} 0} \approx 1.5 \mathrm{eV}$ (intrinsic energy barrier for vacancy hopping in absence of electric field). We are not aware of experimental data about $\mathrm{V}_{\mathrm{O}}^{2+}$ diffusion in $\mathrm{HfO}_{2}$. A theoretical study ${ }^{20}$ predicts that the activation energy for $\mathrm{V}_{\mathrm{O}}^{2+}$ long-range diffusion in $\mathrm{HfO}_{2}$ is around $0.7 \mathrm{eV}$, well below the value found here. Barriers of $1.5 \mathrm{eV}$ were calculated for jumps between neighbored sites, ${ }^{20}$ but they do not correspond to the lowest energy diffusion path $(0.7 \mathrm{eV})$ which is the one that should be observed experimentally. More elaborated models of dendrite growth ${ }^{21}$ may provide a better description of the present data, but they require numerical solving and they were not considered here.

It is interesting to note that a similar law $\left[\mathrm{t}_{\mathrm{d}} \sim \exp (\right.$ $\left.\left.-\mathrm{V} / \mathrm{V}_{0}\right)\right]$ was recently reported for time-dependent switching in conductive bridging memories (CBRAMs) using the diffusion of $\mathrm{Ag}$ in $\mathrm{a}-\mathrm{Si}^{22}$ This points to the similarity of the mechanism involved in both RRAMs and CBRAMs (diffusion of cations, the cations being $\mathrm{V}_{\mathrm{O}}^{2+}$ in the present case, and $\mathrm{Ag}^{+}$in Ref. 22). In Ref. 22 the time $\mathrm{t}_{\mathrm{d}}$ (which was named the "wait" time) was found to follow a Poisson distribution. In PCRAMs, Karpov et al. ${ }^{19}$ also reported a narrow dispersion of $t_{d}$ which was ascribed to heterogeneities of the glassy material. Figure 4(c) shows repetitive measurements performed on the same dot (at $\mathrm{T}=68{ }^{\circ} \mathrm{C}$ and $\mathrm{V}=+3 \mathrm{~V}$ ). Some dispersion is indeed observed, but $t_{d}$ keeps the same order of magnitude during successive measurements. These data are consistent with a deterministic mechanism (diffusion) which is pertubated by some extra parameters, leading to a distribution of $t_{d}$ around a central value. Dispersion in $t_{d}$ values may result from the fact that $\mathrm{V}_{\mathrm{O}}^{2+}$ filaments start growing from different electrode sites (i.e., different nucleation times must be taken into account), or that they follow different paths in the $\mathrm{HfO}_{2}$ film (polycrystalline). The distribution law was not studied and will be the subject of a future work. Therefore, the quoted value of $1.5 \mathrm{eV}$ for $\mathrm{E}_{\mathrm{a} 0}$ should only be considered as a rough estimate.

Within the above model, at a given temperature it is possible to extrapolate the ratio of switching times for two different biases, i.e., $\mathrm{t}_{\mathrm{d}}\left(\mathrm{V}_{1}\right) / \mathrm{t}_{\mathrm{d}}\left(\mathrm{V}_{2}\right)=\exp \left[(-\mathrm{qs} / \mathrm{tkT})^{*}\left(\mathrm{~V}_{1}\right.\right.$ $\left.-\mathrm{V}_{2}\right)$ ]. At $300 \mathrm{~K}$ this relation gives $\mathrm{t}_{\mathrm{d}}(\mathrm{V}=+3.5 \mathrm{~V}) / \mathrm{t}_{\mathrm{d}}(\mathrm{V}=$ $+4 \mathrm{~V}) \approx 17$. In the preceding sections we concluded that the switching time at $+3.5 \mathrm{~V}$ is above $60 \mathrm{~s}$, and less than $1 \mathrm{~s}$ at $+4 \mathrm{~V}$, which would give $t_{d}(V=+3.5 \mathrm{~V}) / \mathrm{t}_{\mathrm{d}}(\mathrm{V}=+4 \mathrm{~V})$ $>60$. Obviously the values are not the same, but the order of magnitude is close. The ratio $t_{d}(V=+3.5 \mathrm{~V}) / \mathrm{t}_{\mathrm{d}}(\mathrm{V}=+4 \mathrm{~V})$ $=60$ would correspond to $\mathrm{s}=10.6 \AA$ and $\mathrm{E}_{\mathrm{a}}=0.75 \mathrm{eV}$ in Fig. 5(a) (instead of $7 \AA$ and $1.05 \mathrm{eV}$ ). Discrepancy results from the lack of the precise determination of $E_{a}$ which would require to study the statistical distribution of $t_{d}$ at various temperatures. Nevertheless, $\mathrm{E}_{\mathrm{a}}$ is well above the activation energy related to the conduction in the OFF state [around 0.3 eV, Fig. 2(b)]. It shows that the traps which control the conduction in the OFF state are not implied in the switching process.

We now turn back to the random switching events observed after the first switch $\left(t>t_{d}\right)$. In the sweeping mode [Fig. 1(a)] the samples have a bipolar behavior. The Reset is obtained only at negative voltages. However, in the CVS mode (Fig. 3) the Reset is obtained for a constant, positive voltage. In that case it is believed that thermal dissolution of the conducting filaments occurs. This is possible if Joule heating is large enough for oxygen vacancies to migrate out of the filaments. Large Joule heating is produced by rising the temperature (above $50{ }^{\circ} \mathrm{C}$ in Fig. 3) and by leaving the film under a constant current stress. Therefore, in the CVS mode the thermal motion of $\mathrm{V}_{\mathrm{O}}^{2+}$ (filament rupture) constantly opposes the effect of the electric field (alignment of $\mathrm{V}_{\mathrm{O}}^{2+}$ in a filamentary structure). This explains the fluctuation between the $\mathrm{ON}$ and $\mathrm{OFF}$ states reported in Figs. 3 and 4. In the sweeping mode (Fig. 1), rupture of conducting filaments does not occur because Joule heating is too brief. More exactly, by referring to the work of Russo et al., ${ }^{23}$ we can postulate that the sweeping rate $(0.35 \mathrm{~V} / \mathrm{s})$ does not provide enough time for a thermal dissolution to take place. Moreover, as sweeping mode experiments are carried out at room temperature (Fig. 1) heat evacuation is enhanced.

The signal observed in the CVS mode bears close resemblance to random telegraph switching noise (RTSN) observed, for instance, in Metal- $\mathrm{SiO}_{2}-\mathrm{Si}$ devices ${ }^{24}$ or in metala-Si:H-metal devices. ${ }^{25}$ In these devices RTSN was ascribed to the random filling-emptying of trap levels ${ }^{24}$ and to the random motion of hydrogen, ${ }^{25}$ respectively. In a-Si:H, Lust and Kakalios ${ }^{25}$ modeled RTNS by a dynamical percolation network where the random movement of hydrogen lead to the creation or elimination of conducting pathways. Percolation networks were recently put forward to explain resistance switching in $\mathrm{TiO}_{2}{ }^{26}$ Therefore, oxygen vacancies in $\mathrm{HfO}_{2}$ could play a similar role to hydrogen in a-Si:H, and random events observed here in the CVS mode could be explained by a dynamical percolation network where $\mathrm{V}_{\mathrm{O}}^{2+}$ migration opens or closes conducting filaments. Finally, in $\mathrm{SiO}_{2}$ it was recently demonstrated that oxygen vacancies are at the origin 

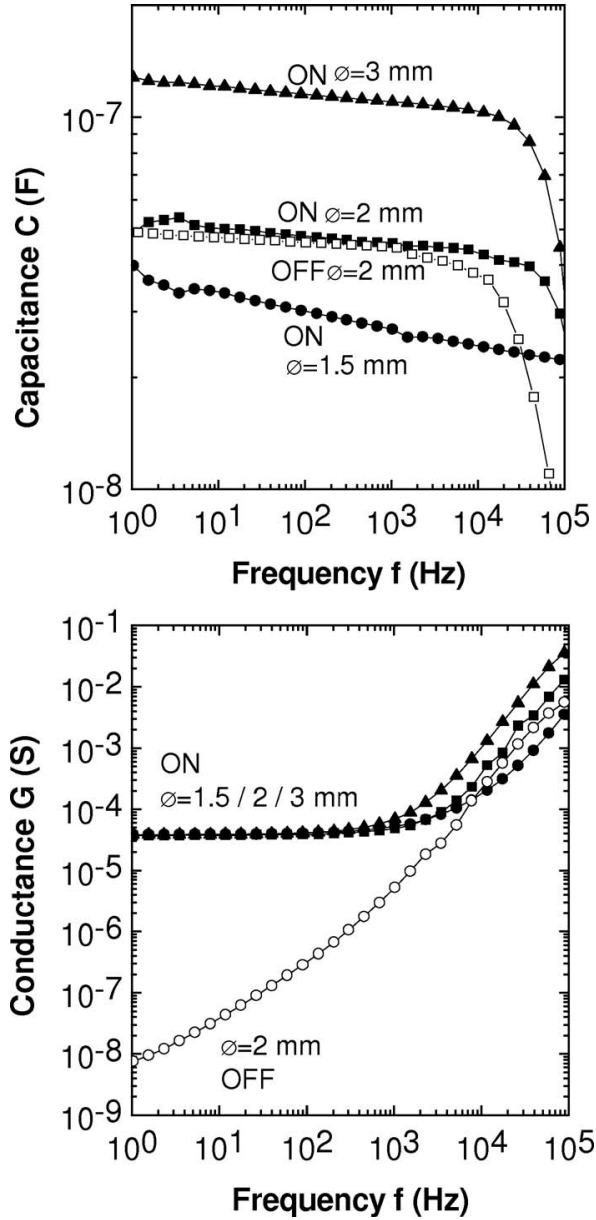

FIG. 6. Frequency dependence of the $\mathrm{C}$ and $\mathrm{G}$ in the $\mathrm{ON}$ and OFF states, as a function of the top electrode size.

of the random telegraph signal (RTS) noise observed in the prebreakdown regime. ${ }^{27}$ In $\mathrm{SiO}_{2}$, a recent theoretical work also shows that breakdown could arise from the percolation of oxygen vacancies. ${ }^{28}$ Thus, in oxides it is more and more apparent that resistance switching and breakdown phenomena are intimately related.

\section{F. Impedance spectroscopy}

Impedance spectroscopy was carried out to gain more information on the ON and OFF states. Figure 6 shows the frequency dependence of the $\mathrm{C}$ and $\mathrm{G}$ for the $\mathrm{ON}$ and $\mathrm{OFF}$ states, as a function of the dot size. Figures 7 and 8 depict $\mathrm{C}$ and $\mathrm{G}$ as a function of temperature, for both states. During these experiments an ac amplitude of $0.1 \mathrm{~V}_{\text {rms }}$ was used (much lower than $\mathrm{V}_{\text {set }}$ and $\mathrm{V}_{\text {reset }}$ so as to not modify the state of resistance).

In the OFF state $G$ increases with frequency in a manner which is typical of insulators where an hopping conduction (electronic or ionic) takes place, i.e., $\mathrm{G}=\mathrm{G}_{\mathrm{dc}}+\mathrm{G}_{0} \omega^{\mathrm{n}}$, where $\mathrm{G}_{\mathrm{dc}}$ is the $\mathrm{G}$ in the dc regime, $\mathrm{n}$ is an exponent which usually ranges between 0.5 and 1 , and $\mathrm{G}_{0}$ is a prefactor. ${ }^{29}$ Below 1 $\mathrm{kHz}, \mathrm{n}$ is found to be around $0.8-0.9$, decreasing with temperature $\left(0.93\right.$ at $50{ }^{\circ} \mathrm{C}$ and 0.81 at $150{ }^{\circ} \mathrm{C}$, Fig. 8). In the same frequency range, $\mathrm{C}$ very slightly decreases with frequency, and slightly decreases with T (Fig. 7).
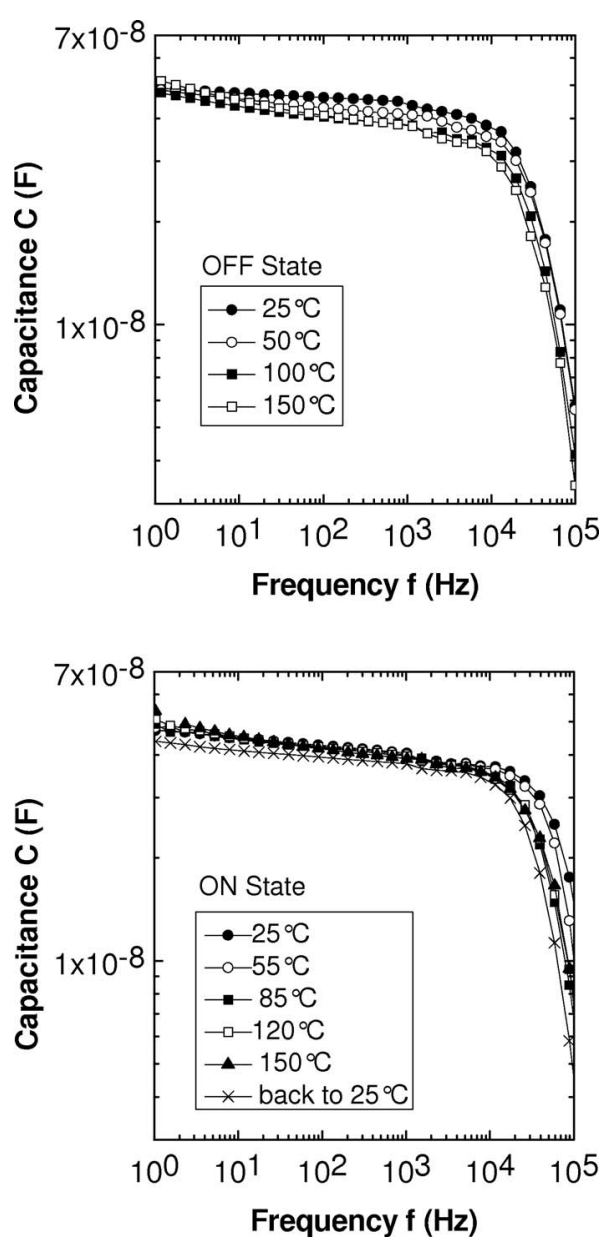

FIG. 7. $\mathrm{C}$ in the $\mathrm{OFF}$ and $\mathrm{ON}$ states, as a function of temperature.

Above $1 \mathrm{kHz}$ the $\mathrm{G}(\mathrm{f})$ slope increases to reach $\mathrm{n}=1.8$, independent of temperature. At the same time $\mathrm{C}$ drops ( $\mathrm{f}$ $>10 \mathrm{kHz}$ ). This could be interpreted as a dielectric relaxation. However, the $\mathrm{n}$ value (1.8) is much too high to be realistic $(\mathrm{n}<1) .{ }^{29}$ Relaxations related to ions motion with $\mathrm{n}$ close to 2 has been observed in glasses, but at much higher frequencies $(\mathrm{f}>\mathrm{GHz}){ }^{30}$ While studying the resistance switching in $\operatorname{Pr}_{0.7} \mathrm{Ca}_{0.3} \mathrm{MnO}_{3}$ oxides, Das et al. ${ }^{31}$ reported a similar drop in $\mathrm{C}$ above $100 \mathrm{kHz}$ which was ascribed to carriers relaxation at deep traps. Contrary to this explanation, here it is thought that the dispersion observed at $\mathrm{f}>1 \mathrm{kHz}$ is due to a series resistance. Let be $R_{s}$ this series resistance $\left(R_{s} \ll R\right.$, where $R=1 / G$ is sample's resistance). Calculation shows that the total $G$ is given by $G_{t}=R_{s} C^{2} \omega^{2}\left(f_{c 1} \ll f \ll f_{c 2}\right)$ and $\mathrm{G}_{\mathrm{t}}=1 / \mathrm{R}_{\mathrm{s}}\left(\mathrm{f}_{\mathrm{c} 2} \ll \mathrm{f}\right)$, where $\mathrm{f}_{\mathrm{c} 1}=1 /\left[2 \pi\left(\mathrm{RR}_{\mathrm{s}}\right)^{1 / 2} \mathrm{C}\right]$ and $\mathrm{fc}_{2}$ $=1 /\left(2 \pi R_{\mathrm{s}} \mathrm{C}\right)$. At the same time, the total $\mathrm{C}$ is given by $\mathrm{C}_{\mathrm{t}}$ $=\mathrm{C}\left(\mathrm{f}_{\mathrm{c} 1} \ll \mathrm{f} \ll \mathrm{f}_{\mathrm{c} 2}\right)$ and $\mathrm{C}_{\mathrm{t}}=1 / \mathrm{R}_{\mathrm{s}}^{2} \mathrm{C} \omega^{2}\left(\mathrm{f}_{\mathrm{c} 2} \ll \mathrm{f}\right)$. A quick look at Fig. 7 shows that $\mathrm{f}_{\mathrm{c} 2} \approx 10^{4} \mathrm{~Hz}$, while a look at Fig. 8 shows that $\mathrm{f}_{\mathrm{cl}} \approx 10^{3} \mathrm{~Hz}$. Because $\mathrm{C}$ slightly decreases with $\mathrm{f}$, the expression $\mathrm{G}_{\mathrm{t}}=\mathrm{R}_{\mathrm{s}} \mathrm{C}^{2} \omega^{2}$ explains why we observe $\mathrm{G}_{\mathrm{t}} \sim \omega^{\mathrm{n}}$ with $n$ close to $2\left(n=1.8\right.$ gives $C \sim \mathrm{f}^{-0.1}$ with the hypothesis that $R_{\mathrm{s}}$ does not vary with $\mathrm{f}$ ). The series resistance is thought to come from the deposited top electrode (rf-sputtered $\mathrm{Au}$ ). Indeed, this electrode was observed by Secondary Electron Microscopy (SEM) to have a granular structure, which may be at the origin of a significant resistance. Since $G_{t}=1 / R_{s}$ $\left(f_{\mathrm{c} 2} \ll f\right)$, the value of $R_{\mathrm{s}}$ can be deduced from the saturation 

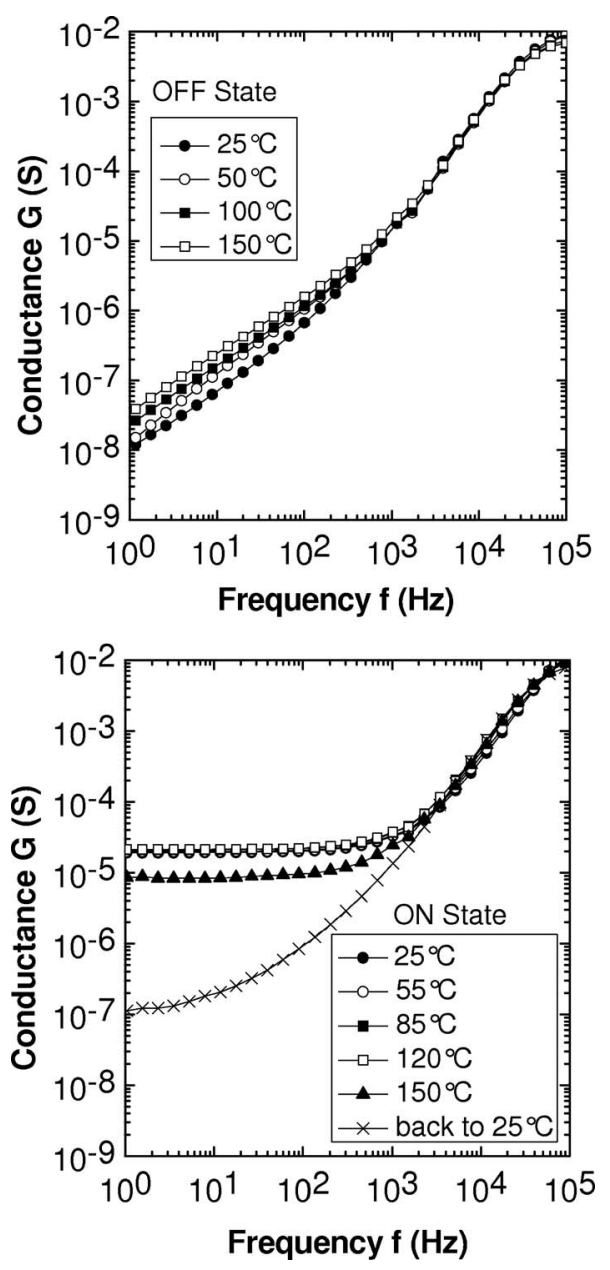

FIG. 8. G in the OFF and ON states, as a function of temperature.

value of the $\mathrm{G}$ at high frequencies. In Fig. 8 beginning of saturation is observed around $100 \mathrm{kHz}$, from which we roughly estimate $R_{s}$ to be in the $10-100 \Omega$ range.

Because of the series resistance only the data below 1 $\mathrm{kHz}$ should be considered to be representative of the oxide (the data above $1 \mathrm{kHz}$ will now be dismissed). In the ON state Fig. 6 shows that $C$ varies like the electrode area. This figure also shows that $\mathrm{C}_{\mathrm{ON}}$ is the same as $\mathrm{C}_{\mathrm{OFF}}$. On the contrary, in the ON state $\mathrm{G}$ is independent of the electrode area. This confirms that conduction in the ON state proceeds through tiny filaments whose section is much smaller that the electrode diameter. It is also seen that $\mathrm{G}_{\mathrm{ON}}$ is constant with frequency (plateau), at least up to $1 \mathrm{kHz}$ (dispersion above 1 $\mathrm{kHz}$ is due to the series resistance). Thus, if an hopping conduction proceeds through $\mathrm{V}_{\mathrm{O}}^{2+}$ defects its cut-off frequency should be well above $1 \mathrm{kHz}$. The $\mathrm{G}_{\mathrm{ON}}$ value measured by impedance spectroscopy (between $10^{-4}$ and $10^{-5} \mathrm{~S}$ ) agrees with the current values measured in a sweeping mode [between $10^{-4}$ and $10^{-5} \mathrm{~A}$ at $1 \mathrm{~V}$, see Fig. 1(a)]. From these results, the device can be simply described by a $\mathrm{R}_{\mathrm{OFF}} \| \mathrm{C}$ cell for which $\mathrm{R}_{\mathrm{OFF}}$ is shunted by $\mathrm{R}_{\mathrm{ON}}$ when the device is in the ON state.

Figure 7 confirms that $\mathrm{C}_{\mathrm{ON}}$ is the same as $\mathrm{C}_{\mathrm{OFF}}$ (most of the $\mathrm{HfO}_{2}$ bulk is not affected by switching), and that $\mathrm{C}_{\mathrm{ON}}$ is stable with temperature. In Fig. 2 it was observed that $\mathrm{R}_{\mathrm{ON}}$ is unstable with temperature. This is again observed in Fig. 8 .
(ON state). At $150{ }^{\circ} \mathrm{C} \mathrm{G}_{\mathrm{ON}}$ decreases. While the sample is cooled down to $25{ }^{\circ} \mathrm{C}$, the sample (which is short-circuited by the impedance meter during the cooling stage) returns back to a high resistance state (about one order of magnitude above the OFF state), consistent with a thermal dissolution of the conducting filaments as discussed previously.

\section{CONCLUSION}

Resistance switching was studied in $10 \mathrm{~nm} \mathrm{HfO}_{2}$ films deposited by ALD. The following conclusions were reached:

- Regarding general properties, $\mathrm{Au} / \mathrm{HfO}_{2}(10 \mathrm{~nm}) / \mathrm{Pt}$ stacks provide good resistance switching characteristics (ON/OFF ratio $>10^{4}$, very reproducible $\mathrm{V}_{\text {set }}$, absence of forming). However, $\mathrm{V}_{\text {reset }}$ shows dispersion. The very low activation energy of the ON state (11 $\mathrm{meV}$ ) is compatible with a tunnel conduction (hopping between $\mathrm{V}_{\mathrm{O}}^{2+}$ ). The device can only be reset by applying negative biases (bipolar only). Conduction in the OFF state is controlled by a distribution of traps around $0.3 \mathrm{eV}$. The memory can be described by a RC parallel cell where $\mathrm{C}$ is the same for the $\mathrm{ON}$ and OFF states, and $\mathrm{R}_{\mathrm{OFF}}$ is shunted by $\mathrm{R}_{\mathrm{ON}}$ in the $\mathrm{ON}$ state (filamentary conduction). No noticeable dispersion of ac characteristics is observed until $1 \mathrm{kHz}$. Dispersion above $1 \mathrm{kHz}$ is due to electrode artifacts (series resistance). Important characteristics for integration, such as endurance and retention time over long periods, were not addressed and need to be studied in a future work.

- Instabilities of various kinds were observed. The ON state is not maintained for "negative cycles," i.e., when vacancy filaments are grown on the Au electrode. This behavior was ascribed to a weak $\mathrm{Au}-\mathrm{V}_{\mathrm{O}}$ binding energy, or to the back-diffusion of $\mathrm{O}^{2-}$ from the buried $\mathrm{Pt}$ electrode. Reset is not possible when using a bottom TiN electrode. This is a serious drawback for future integration. Toward this goal, more work is needed to understand the role played by the $\mathrm{TiO}_{\mathrm{x}} \mathrm{N}_{\mathrm{y}}$ interfacial layer. Finally, it was noted that the ON state is thermally unstable $\left(>100{ }^{\circ} \mathrm{C}\right)$. Such an instability can be explained by the thermal dissolution of vacancy filaments.

- Switching dynamics can be studied by comparing different bias modes. The CVS mode reveals interesting features. The delay time to the first switch is found to be thermally activated and to vary exponentially with the voltage. This is consistent with a filament growth which is governed by $\mathrm{V}_{\mathrm{O}}^{2+}$ diffusion (activation energy around $1.5 \mathrm{eV}$ ). After the first switch, ON-OFF transitions randomly occur in time, quite similar to RTS usually observed in prebreakdown regimes. It was proposed that these random instabilities result from a competition between the thermal dissolution of $\mathrm{V}_{\mathrm{O}}^{2+}$ filaments and their reconstruction upon the alignment of $\mathrm{V}_{\mathrm{O}}^{2+}$ along the electric field.

${ }^{1}$ T. W. Hickmott, J. Appl. Phys. 33, 2669 (1962).

${ }^{2}$ See, for instance, IEEE Trans. Electron Devices 20, 89 (1973) special 
issue on amorphous semiconductor devices, edited by A. I. Bienenstock, C. W. Bates, and W. Spicer.

${ }^{3}$ R. Waser, R. Dittmann, G. Staikov, and K. Szot, Adv. Mater. 21, 2632 (2009).

${ }^{4}$ B. Gao, B. Sun, H. Zhang, L. Liu, W. Liu, R. Han, J. Kang, and B. Yu, IEEE Electron Device Lett. 30, 1326 (2009).

${ }^{5}$ M. D. Pickett, D. B. Strukov, J. L. Borghetti, J. J. Yang, G. S. Snider, D. R. Stewart, and R. S. Williams, J. Appl. Phys. 106, 074508 (2009).

${ }^{6}$ A. Kerber and E. A. Cartier, IEEE Trans. Device Mater. Reliab. 9, 147 (2009).

${ }^{7}$ Ch. Walczyk, Ch. Wenger, R. Sohal, M. Lukosius, A. Fox, J. Dabrowski, D. Wolansky, B. Tillack, H.-J. Müssig, and T. Schroeder, J. Appl. Phys. 105, 114103 (2009).

${ }^{8}$ H. Y. Lee, P.-S. Chen, T.-Y. Wu, Y. S. Chen, F. Chen, C.-C. Wang, P.-J. Tzeng, C. H. Lin, M.-J. Tsai, and C. Lien, IEEE Electron Device Lett. 30, 703 (2009).

${ }^{9}$ S. Lee, W.-G. Kim, S.-W. Rhee, and K. Yong, J. Electrochem. Soc. 155 , H92 (2008).

${ }^{10}$ H. Y. Lee, P. S. Chen, T. Y. Wu, C. C. Wang, P. J. Tzeng, C. H. Lin, F. Chen, M.-J. Tsai, and C. Lien, Appl. Phys. Lett. 92, 142911 (2008).

${ }^{11}$ Y.-M. Kim and J.-S. Lee, J. Appl. Phys. 104, 114115 (2008).

${ }^{12}$ M. Y. Chan, T. Zhang, V. Ho, and P. S. Lee, Microelectron. Eng. 85, 2420 (2008).

${ }^{13}$ C. Jorel, C. Vallée, E. Gourvest, B. Pelissier, M. Kahn, M. Bonvalot, and P. Gonon, J. Vac. Sci. Technol. B 27, 378 (2009).

${ }^{14}$ K. M. Neyman, C. Inntam, A. V. Matveev, V. A. Nasluzov, and N. Rösch, J. Am. Chem. Soc. 127, 11652 (2005).

${ }^{15}$ X.-Q. Gong, A. Selloni, O. Dulub, P. Jacobson, and U. Diebold, J. Am. Chem. Soc. 130, 370 (2008).
${ }^{16}$ D. S. Jeong, H. Schroeder, U. Breuer, and R. Waser, J. Appl. Phys. 104, 123716 (2008).

${ }^{17}$ J. Zimmermann, M. W. Finnis, and L. Colombi Ciacchi, J. Chem. Phys. 130, 134714 (2009).

${ }^{18}$ J. L. Barton and J. O’M. Bockris, Proc. R. Soc. London, Ser. A 268, 485 (1962).

${ }^{19}$ I. V. Karpov, M. Mitra, D. Kau, G. Spadini, Y. A. Kryukov, and V. G. Karpov, Appl. Phys. Lett. 92, 173501 (2008); V. G. Karpov, Y. A. Kryukov, M. Mitra, and I. V. Karpov, J. Appl. Phys. 104, 054507 (2008).

${ }^{20}$ N. Capron, P. Broqvist, and A. Pasquarello, Appl. Phys. Lett. 91, 192905 (2007).

${ }^{21}$ C. Monroe and J. Newman, J. Electrochem. Soc. 150, A1377 (2003).

${ }^{22}$ S. H. Jo, K.-H. Kim, and W. Lu, Nano Lett. 9, 496 (2009).

${ }^{23}$ U. Russo, D. Ielmini, C. Cagli, and A. L. Lacaita, IEEE Trans. Electron Devices 56, 186 (2009).

${ }^{24}$ K. R. Farmer, C. T. Rogers, and R. A. Buhrman, Phys. Rev. Lett. 58, 2255 (1987).

${ }^{25}$ L. M. Lust and J. Kakalios, Phys. Rev. Lett. 75, 2192 (1995).

${ }^{26}$ S. C. Chae, J. S. Lee, S. Kim, S. B. Lee, S. H. Chang, C. Liu, B. Kahng, H. Shin, D.-W. Kim, C. U. Jung, S. Seo, M.-J. Lee, and T. W. Noh, Adv. Mater. 20, 1154 (2008).

${ }^{27}$ X. Li, C. H. Tung, K. L. Pey, and V. L. Lo, Appl. Phys. Lett. 94, 132904 (2009).

${ }^{28}$ J. Kang, Y.-H. Kim, J. Bang, and K. J. Chang, Phys. Rev. B 77, 195321 (2008).

${ }^{29}$ D. L. Sidebottom, Phys. Rev. B 61, 14507 (2000).

${ }^{30}$ K. Funke and R. D. Banhatti, Solid State Sci. 10, 790 (2008).

${ }^{31}$ N. Das, S. Tsui, Y. Y. Xue, Y. Q. Wang, and C. W. Chu, Phys. Rev. B 78, 235418 (2008). 